Research Paper

\title{
Combustion and Emission Characteristics of Combined PCCI and Conventional Diesel Combustion
}

\author{
Zhichao Bao ${ }^{\text {1) Weikang Pan }}{ }^{2)}$ Yinzhe Gu $^{2)}$ Naoto Horibe ${ }^{2)}$

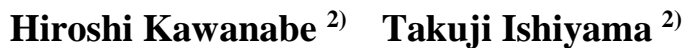 \\ 1) Kyoto University, Graduate School of Energy Science \\ Yoshidahonmachi, Sakyo Ward, Kyoto,606-8501, Japan (E-mail: bao.chishao.64z@st.kyoto-u.ac.jp) \\ 2) Kyoto University, Graduate School of Energy Science \\ Yoshidahonmachi, Sakyo Ward, Kyoto, 606-8501, Japan
}

Received on August, 8,2019

\begin{abstract}
Previously, some efforts were made to investigate the effect of combining premixed charge compression ignition (PCCI) combustion with conventional mixing controlled combustion using two injectors for single cylinder. In this experiment, the PCCI combustion was introduced by a sub injection fixed at early stage and the conventional diesel combustion was introduced by main injection starts near top dead center (TDC). The self-ignitability of sub injection fuel was modified by blending n-heptane and isooctane. Therefore, the ignition delay of PCCI combustion was extended to overlap with conventional diesel combustion near TDC by increasing the isooctane volume percentage in sub fuel. By overlapping PCCI and conventional diesel combustion, the cooling loss could be reduced. Later, the combustion and emission characteristics of the combined combustion strategy was examined. The experimental results showed that with larger PCCI combustion ratio at the fixed load, the degree of constant volume (DCV) increased. At the same time, the cooling loss was decreased slightly.
\end{abstract}

KEY WORDS: Premixed charge compression ignition, Multi-injection; Cooling loss, Spray combustion, Combustion characteristics [A1].

\section{Introduction}

Diesel engines play a prime role in the transportation sector because of their superior fuel consumption, high torque at low speed, durability and reliability. However, high NOx and PM emissions and their trade-off relation are the major problems to be addressed. To cope with the ever-tightening emission regulations while increasing thermal efficiency, several strategies were investigated. The diesel based premixed charge compression ignition (PCCI) has been studying since nearly 30 years ago ${ }^{(1-3)}$. In PCCI engine, a lean air fuel mixture is well formed before chemical reaction and the ignition is triggered by compression. Soot formation is naturally avoided because the mixture is sufficiently lean. NOx is reduced because of relatively low combustion temperature (burning-gas and burnt-gas temperature). Later, many researches were conducted to investigate combustion characteristics of lean uniform mixture with wide range of operation conditions ${ }^{(4-7)}$. For PCCI combustion, the ignition timing can be too early when using ordinary diesel fuel, resulting in lower thermal efficiency. Furthermore, PCCI combustion is usually very rapid featuring a high rate of pressure rise. Therefore, PCCI combustion is usually restricted to low load conditions ${ }^{(8,9)}$. In addition, the early direct injection could increase the smoke and $\mathrm{CO}$ emission due to the wall wetting effect. To solve this problem, the narrow angle direct injection (NADI) combustion concept has been developed $^{(10)}$. In this technique, the combustion chamber was deliberately designed to optimize the spray formation to facilitate both early injection and conventional near top dead center (TDC) injection. The narrow injection angle (lower than 100 degrees) allows the fuel to be injected early in the compression stroke without causing cylinder liner wetting.

Another PCCI combustion strategy for suppressing NOx emission is called premixed lean diesel combustion (PREDIC) system. This system consists of two injectors located at two sides of the combustion chamber. Thus, the spray impingement helps to form an air-fuel mixture at the center of the combustion chamber, resulting in a decrease in cylinder wall wetting with a long ignition delay period ${ }^{(11-13)}$. As a result, low NOx and smoke emissions were simultaneously achieved. However, this technique is restricted to partial load condition. Other techniques applied high EGR rate and late injection timing (20 to 30 BTDC) to avoid the wall wetting and early ignition brought by early injection. These study reported low NOx and PM. But the operation condition was restricted to low load since the high EGR rate will bring high $\mathrm{CO}$ emission when injection quantity is large. Therefore, in this study, our target was set to search the possibility of applying PCCI combustion at high load condition. One example is called multiple stage diesel combustion (MULDIC) ${ }^{(14)}$. The MULDIC system adopted a multiple stage injection strategy, which introduced fuel spray from three injectors: two located at the side of the chamber and one center injector. The first stage combustion was PCCI combustion produced by the side injectors, while the second stage combustion was the conventional diffusive combustion controlled by the center injector. NOx reduction was 
Vol.10, No.4(2019)

achieved even under high load conditions but the thermal efficiency was lower than that of conventional operation. In our laboratory, we proposed a new combustion strategy to synchronize the PCCI combustion with conventional diesel combustion $^{(15)}$. The schematic of the combustion concept is shown on Figure 1. PCCI-based combustion was achieved by early direct injection (sub injection) and conventional diesel combustion was introduced by main injection near TDC. We aimed to shorten the overall combustion duration by synchronizing two types of combustion. When this is achieved, the degree of constant volume (DCV) is expected to increase. Commonly, the cooling loss will increase with DCV. However, in this case, the cooling loss was expected to be lower compared to conventional center injection due to the following two reasons. Firstly, the main spray impingement is reduced. Secondly, if the air-fuel mixture by sub injection is sufficiently lean, the sub combustion will be characterized with low temperature combustion. Furthermore, the fuel used for PCCI combustion is distributed avoiding the center of the combustion chamber in order not to prevent the oxygen entrainment into the main spray.

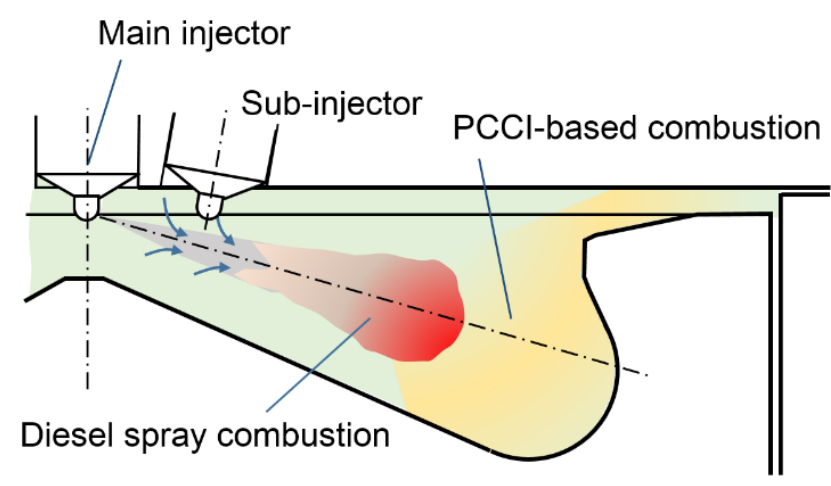

Fig. 1 Schematic of combustion concept.

The previous study revealed some problems of this combustion strategy. At first, the ignition delay of PCCI combustion was too short to realize the overlap with main combustion. Secondly, smoke emission was at high level due to the wall wetting of the sub injection spray. At last, the cooling loss reduction by combining PCCI combustion was failed because of combustion of fuel adhered on the wall. The previous study also indicated that using primary reference fuel, such as n-heptane could reduce the wall wetting thus the problems concerned about smoke emission and cooling loss was solved. In order to justify the effect of the proposed combustion strategy on cooling reduction and DCV improvement, the ideal combustion phase characterized by the overlap of PCCI combustion and conventional diesel combustion should be realized. In this experiment, different volume percentages of $\mathrm{n}$-heptane and isooctane was blended to adjust the ignitability of sub fuel so that the expected combustion phase could be acquired ${ }^{(16-18)}$. A single cylinder diesel engine was used to investigate the effect of PCCI combustion timing on main combustion and emission characteristics. Later, the cooling loss reduction effect of PCCI combustion was researched by modifying the ratio of heat input for sub and main injection.

\section{Experimental Setup}

In this experiment, we used a single cylinder four stroke diesel engine with a dual-injection system. One is a high-pressure main injection system and the other is an early narrow-angle sub injection system. The main injection and sub-injection parameters can be changed separately. The schematic of experimental system is shown in Figure 2. The bore and stroke of the engine were 85 $\mathrm{mm}$ and $96.9 \mathrm{~mm}$, respectively. The engine displacement was $0.55 \mathrm{~L}$. The compression ratio was set to a rather low level of 15.5 in order to ensure sufficient ignition delay of PCCI-based combustion. Major specifications of the engine can be found on Table 1.

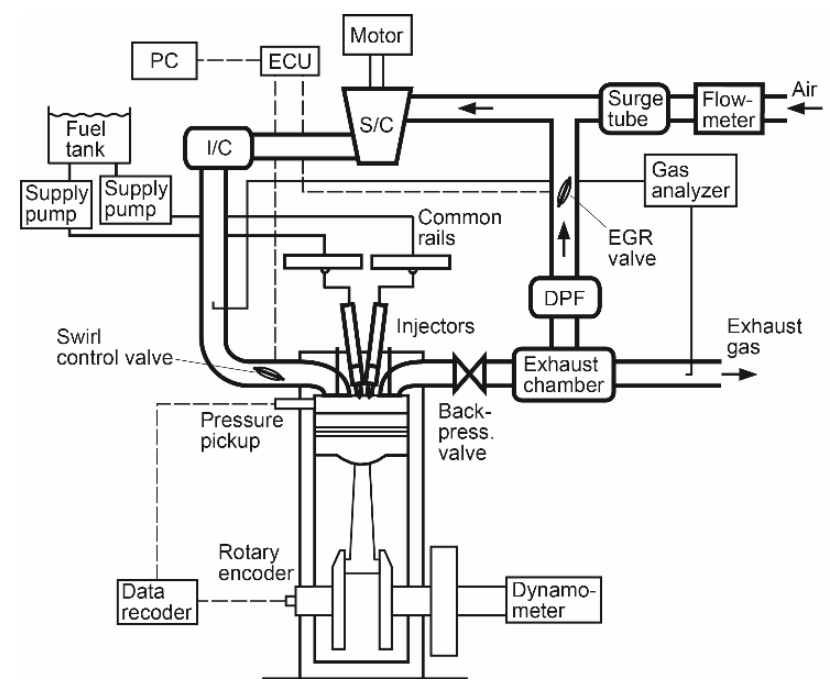

Fig. 2 The schematic of experimental setup.

Table 1 The major specifications of the engine.

\begin{tabular}{|c|c|}
\hline Engine type & $\begin{array}{c}\text { Direct-injection diesel engine, } \\
\text { Single-cylinder, Water-cooled }\end{array}$ \\
\hline Bore $\times$ Stroke $[\mathrm{mm}]$ & $85.0 \times 96.9$ \\
\hline Displacement $\left[\mathrm{cm}^{3}\right]$ & 550 \\
\hline Injection system & $\begin{array}{c}\text { Two independent } \\
\text { common-rail system }\end{array}$ \\
\hline Charging & External supercharging \\
\hline EGR system & Low-pressure loop EGR \\
\hline
\end{tabular}

Two piezo injectors with two individual common rail systems were utilized and the main injector was located at the center of the combustion chamber while the sub-injector has 15 $\mathrm{mm}$ offset from the center. The two injectors had the same nozzle diameter of $0.104 \mathrm{~mm}$ but different injection angle and the number of nozzle hole. The sub-injection angle was set to $50^{\circ}$ based on the results of preliminary study using computational fluid dynamics simulation. This adequate injection angle allowed the premixed fuel to distribute at the periphery of the combustion chamber while avoiding oil dilution with early injection. The main injection angle was set to $156^{\circ}$ and the nozzle number was 10. However, the nozzle number of sub-injector was set to 5 due to the manufacturing limitation. The injection direction and its relation with combustion chamber are illustrated on Figure 3. The fuel pump was driven by external driving electric motor and the injection pressure for sub and main injection was fixed to 150 $\mathrm{MPa}$ and $200 \mathrm{MPa}$, respectively. 


\section{Zhichao Bao et al / International Journal of Automotive Engineering}

Vol.10, No.4(2019)

In this study, we examined the characteristics of combined combustion at $2250 \mathrm{rpm}$. The total heat input was set to 1410 $\mathrm{J} /$ cycle and, as a result, the gross indicated mean effective pressure was around $1220 \mathrm{kPa}$, which is close to the maximum efficiency point of the original engine at $2250 \mathrm{rpm}$. Intake and exhaust pressure were set to $180 \mathrm{kPa}$ and the intake temperature was $50^{\circ} \mathrm{C}$. The coolant temperature and lubricating oil temperatures were kept at $80^{\circ} \mathrm{C}$. In addition, the intake oxygen concentration intake oxygen concentration was set to $19 \%$ by changing the exhaust gas recirculation (EGR) rate.
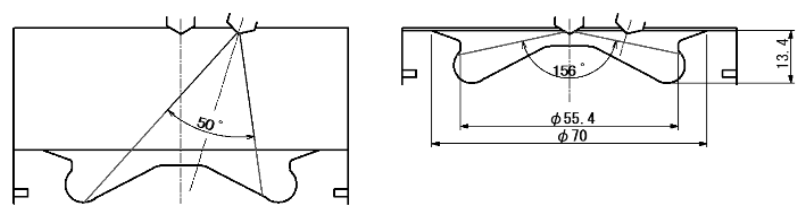

Fig. 3 The injection direction of sub injection (left) and the main injection (right) and their relation to the combustion chamber.

The fuel characteristics of diesel fuel used for main injection are listed in Table 2. For sub injection, blended fuel of n-heptane and isooctane (2,2,4-trimethylpentane) were used. The properties of isooctane and n-heptane are shown in Table 3. The boiling point data in Table 3 is lower compared to the distilling temperature in Table 2. Therefore, we can conclude that they have higher volatility than diesel fuel. By changing the volume percentage of isooctane $\left(r_{i-\mathrm{C} 8 \mathrm{H} 18}\right)$ and n-heptane in the blended fuel, its self-ignitability was modified. In this study, 5 types of fuel were used for sub injection. Their properties are summarized in Table 4.

Table 2. The characteristics of the diesel fuel used for main

\begin{tabular}{c|c} 
& Diesel \\
\hline Cetane number & 55 (cetane index) \\
\hline Octane number & - \\
\hline Lower heating value $[\mathrm{MJ} / \mathrm{kg}]$ & $42.9 \sim 43.3$ \\
\hline Density at $15^{\circ} \mathrm{C}[\mathrm{kg} / \mathrm{m} 3]$ & $837.4 \sim 844.2$ \\
\hline $\mathrm{C}[$ mass $\%]$ & $85.8 \sim 86.7$ \\
\hline $\mathrm{H}[$ mass $\%]$ & $13.6 \sim 13.8$ \\
\hline $\mathrm{N}[$ mass $\%]$ & $<0.1$ \\
\hline $10 \%$ distillation temperature $[\mathrm{K}]$ & 484.15 \\
\hline $50 \%$ distillation temperature $[\mathrm{K}]$ & 557.65 \\
\hline $90 \%$ distillation temperature $[\mathrm{K}]$ & 616.65 \\
\hline
\end{tabular}

In order to protect the fuel pressure pump of sub injection system, 200 vol.ppm fatty acid ethyl ester fuel type lubricity improver (Infineum R655) was added to the sub fuel. Given that the mixing ratio of the lubricity improver was infinitesimal, it is considered that its influence on combustion was neglected ${ }^{(20)}$.

An engine exhaust gas analyzer was used to measure the NOx, THC, $\mathrm{CO}, \mathrm{CO} 2$, and $\mathrm{O} 2$ concentrations. In addition, the smoke emissions were acquired using a filter-type smoke meter.
The heat release rates were calculated from the in-cylinder pressure history (50-cycle average) recorded by a pressure sensor. Table 3. The characteristics of the isooctane and n-heptane used for sub injection.

\begin{tabular}{c|c|c} 
& isooctane & n-heptane \\
\hline Cetane number ${ }^{(19)}$ & 12 & 53 \\
\hline Octane number & 100 & 0 \\
\hline Lower heating value $[\mathrm{MJ} / \mathrm{kg}]$ & 44.3 & 44.6 \\
\hline Density at $15^{\circ} \mathrm{C}\left[\mathrm{kg} / \mathrm{m}^{3}\right]$ & 692 & 687 \\
\hline Boiling point $[\mathrm{K}]$ & 372.1 & 371.6 \\
\hline
\end{tabular}

In this study, the DCV was calculated by the following equation.

$$
D C V=\frac{1}{\eta_{t h} Q_{t}} \int\left[1-\left(\frac{V_{h}+V_{c}}{V_{\theta}}\right)^{1-\kappa}\right] \frac{d Q_{a}}{d \theta} d \theta
$$

where $V_{\mathrm{h}}, V_{\mathrm{c}}$, and $V_{\theta}$ are displacement volume, clearance volume, and in-cylinder volume at a crank angle $\theta$. The $\eta_{\text {th }}$ is the theoretical thermal efficiency of Otto cycle. In addition, $Q_{\mathrm{t}}$ refers to the total heat release including apparent heat release and cooling loss. In order to exclude the influence of cooling loss on $\mathrm{DCV}$, the $\mathrm{d} Q_{\mathrm{a}} / \mathrm{d} \theta$ represents the total heat release rate, which was the sum of cooling loss rate and apparent heat release rate. In this equation, the cooling loss rate was calculated by Woschni's method. However, the cooling loss used for heat balance is calculated by subtracting indicated work, unburned loss, and exhaust loss from total heat input. The rate of exhaust loss was calculated by subtracting intake enthalpy from exhaust enthalpy.

\section{Results and Discussions}

\subsection{The experiments with various sub injection properties}

In the previous study, when n-heptane was used for sub injection, the ignition delay of sub injection was still too short to achieve the overlap of sub and main combustion. Therefore, in this study, the ignition delay was further extended by blending isooctane with n-heptane. Then, the characteristics of the combustion were investigated.

The sub injection timing $\left(\theta_{\text {sub }}\right)$ was fixed at $-60^{\circ}$ ATDC and the fuels listed on Table 4 were used for sub injection. In this series of experiments, though the fuel properties of sub injection were changed, the heat input of sub injection $\left(Q_{\text {sub }}\right)$ was fixed at $360 \mathrm{~J} /$ cycle while that of the main injection $\left(Q_{\text {main }}\right)$ was 1050 $\mathrm{J} /$ cycle. The injection parameters of this series of experiments are summarized in Table 5.

Table 4. The characteristics of the blended fuel for sub injection.

\begin{tabular}{c|c|c|c|c|c} 
Fuel No. & 1 & 2 & 3 & 4 & 5 \\
\hline \hline Cetane number $^{(19)}$ & 53 & 40 & 26 & 19 & 12 \\
\hline Octane number & 0 & 32 & 66 & 83 & 100 \\
\hline n-heptane [volume\%] & 100 & 68 & 34 & 17 & 0 \\
\hline Isooctane [volume\%] & 0 & 32 & 66 & 83 & 100 \\
\hline
\end{tabular}


Vol.10, No.4(2019)

Table 5. The injection parameters of the experiments with various sub injection fuel property.

\begin{tabular}{c|c|c} 
& $\begin{array}{c}\text { Sub- } \\
\text { injection }\end{array}$ & $\begin{array}{c}\text { Main } \\
\text { injection }\end{array}$ \\
\hline Heat input $[\mathrm{J} /$ cycle] & 360 & 1050 \\
\hline Injection timing $\left[{ }^{\circ} \mathrm{ATDC}\right]$ & -60 & -2 \\
\hline Fuel type & $\begin{array}{c}\text { Blended } \\
\text { fuel }\end{array}$ & Diesel \\
\hline
\end{tabular}

$$
Q_{\text {sub }} / Q_{\text {main }}=360 / 1050[\mathrm{~J} / \text { cycle }] ; \theta_{\text {sub }}=-60^{\circ} \text { ATDC }
$$

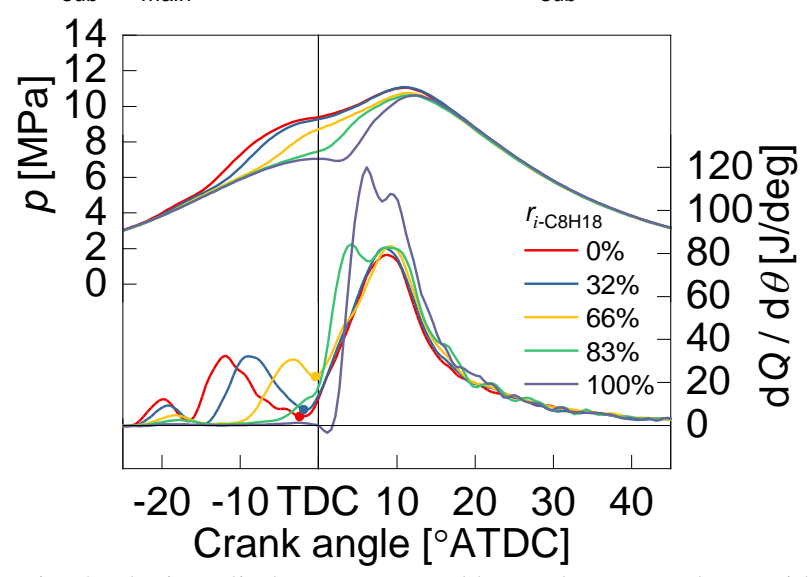

Fig. 4 The in-cylinder pressure and heat release rate shape with various sub injection fuel property.

The in-cylinder pressure $(p)$ and heat release rate $(\mathrm{d} Q / \mathrm{d} \theta)$ shape are shown in Figure 4. The heat release peak observed near $-20^{\circ}$ ATDC could be attributed to the heat release of low temperature oxidation of the sub injection fuel. Then the high temperature oxidation of the sub fuel caused the second peak. It was ranged from $-15^{\circ} \mathrm{ATDC}$ to $5^{\circ} \mathrm{ATDC}$ and its timing was depended on the $r_{i-\mathrm{C} 8 \mathrm{H} 18}$ of the sub fuel. Overall, for PCCI combustion, with the increase of the $r_{i-\mathrm{C} 8 \mathrm{H} 18}$, peak of the low temperature heat release decreased and the ignition timing of high temperature heat release retarded. If we define the timing of main combustion start as the lowest point of the heat release between the peak of PCCI high temperature heat release and main heat release as pointed out in Figure 4, the ignition timing of main combustion retarded with the increase of $r_{i-\mathrm{C} 8 \mathrm{H} 18}$ when $r_{i-\mathrm{C} 8 \mathrm{H} 18}$ was ranged from 0 to $66 \%$. On the other hand, when the $r_{i-\mathrm{C} 8 \mathrm{H} 18}$ was 83 and $100 \%$, the heat release of the high temperature oxidation of sub injection overlapped with the heat release of the main injection. For the experiment with the $r_{i-\mathrm{C} 8 \mathrm{H} 18}$ of $83 \%$, the heat release of sub injection was integrated with that of main injection from 0 to $5^{\circ} \mathrm{ATDC}$ and the ignition timing of the main combustion was difficult to define. On the other hand, the ignition delay of the main injection was obviously retarded when $r_{i-\mathrm{C} 8 \mathrm{H} 18}$ was $100 \%$. When $r_{i-\mathrm{C} 8 \mathrm{H} 18}$ was between 0 to $66 \%$, the main spray may entrain the hot burnt gas produced by sub combustion thus the ignition delay of the main injection was shortened. However, with the increase of $r_{i-\mathrm{C} 8 \mathrm{H} 18}$, the sub combustion timing retarded. Therefore, the effect of triggering main spray ignition by the combustion of sub spray could no longer be observed. As a result, when $r_{i-\mathrm{C} 8 \mathrm{H} 18}$ is $100 \%$, the heat release of main and sub combustion were merged temporally at later stage compared to other experiments. In summary, with the increase of $r_{i-\mathrm{C} 8 \mathrm{H} 18}$, the ignition delay of the sub injection was extended. The overlap of the PCCI combustion and conventional diesel combustion was achieved when $r_{i-\mathrm{C} 8 \mathrm{H} 18}$ was 83 and $100 \%$.

The Figure 5 shows the cooling loss ratio $\left(X_{Q_{\mathrm{c}}}\right), \mathrm{DCV}$, and gross indicated thermal efficiency $\left(\eta_{i-\text { gross }}\right)$ with various sub injection fuel. The DCV did not show an obvious change but the $X_{Q_{\mathrm{c}}}$ decreased with the increase of $r_{i-\mathrm{C} 8 \mathrm{H} 18}$ in sub injection fuel. The shortening of the combustion phase may reduce the contact duration of high-temperature mixture formed by combustion with the combustion chamber wall thus the heat transfer through the chamber wall was decreased. In addition, when $r_{i-\mathrm{C} 8 \mathrm{H} 18}$ was changed from $83 \%$ to $100 \%$, the combustion phase of PCCI combustion retarded behind TDC. Therefore, the combustion temperature will be lower when PCCI combustion occurs at expansion stroke. As a result, with the increase of $r_{i-\mathrm{C} 8 \mathrm{H} 18}$, the $X_{Q_{c}}$ decreased and the $\eta_{i-\text { gross }}$ showed an increase.

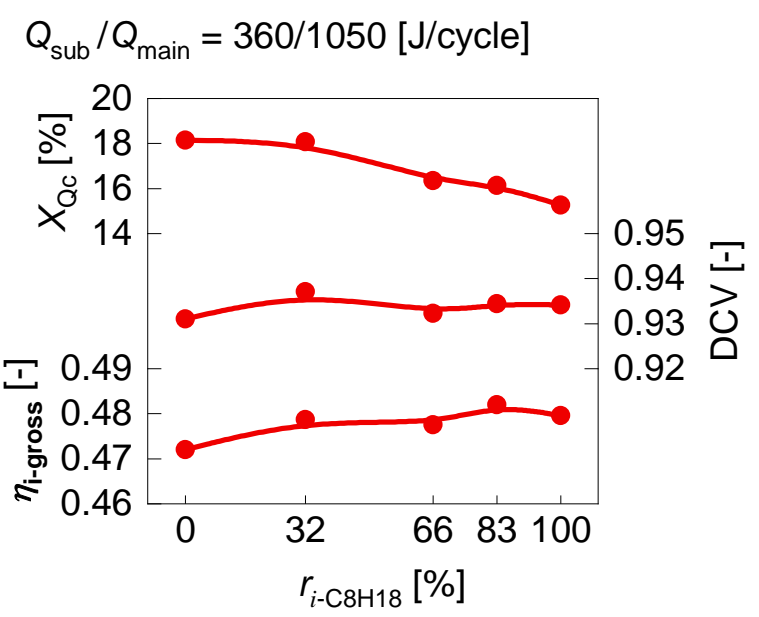

Fig.5 The engine performance with various sub injection fuel property.

The emission results are shown in Figure 6. THC and CO emissions increased slightly with the increase of $r_{i-\mathrm{C} 8 \mathrm{H} 18}$. The longer ignition delay of the sub injection may cause the over lean mixture. Thus, more mixture may contact with the chamber wall with low temperature such as squish area given longer ignition delay. As a result, more THC and CO may be formed by PCCI combustion and its oxidization will be suppressed when ignition delay was longer. The NOx emission decreased when $r_{i-\mathrm{C} 8 \mathrm{H} 18}$ was larger. With the increase of $r_{i-\mathrm{C} 8 \mathrm{H} 18}$, the ignition delay was longer and sub mixture was leaner. Thus, the sub combustion temperature should be lower and NOx formation will be depressed. On the other hand, when the sub and main combustion do not overlap with each other $\left(r_{i-\mathrm{C} 8 \mathrm{H} 18}=0 \%, 32 \%\right)$, the main spray entrained the hot gas produced by sub combustion. Then the temperature of the main spray will rise and, as a result, the NOx emission will increase. The characteristics of the combustion and its effect on emission production will be further discussed in the following sections.

\subsection{The experiments with various main injection timing}




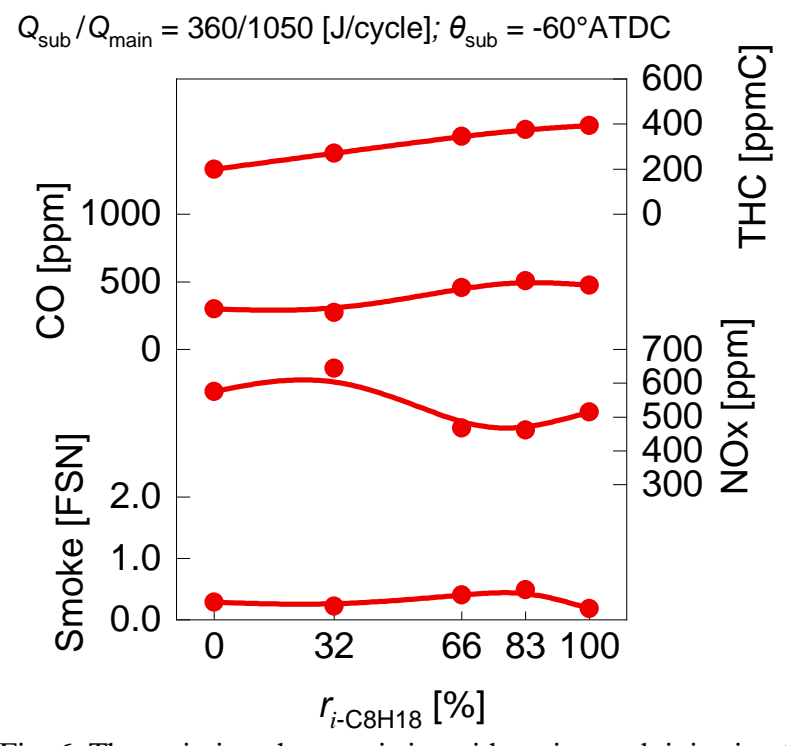

Fig. 6 The emission characteristics with various sub injection fuel property.

In order to investigate the characteristics of the overlapped combustion of sub and main injection, the main injection timing was retarded to separate the heat release of sub and main injection. The No.4 fuel with the $r_{i-\mathrm{C} 8 \mathrm{H} 18}$ of $83 \%$ was used for sub injection. The heat input was the same as the previous experiments while the main injection timing $\left(\theta_{\text {main }}\right)$ was modified from $-2^{\circ}$ ATDC to $6^{\circ}$ ATDC. The injection pressure and intake oxygen concentration were unchanged. Detailed injection parameters are summarized on Table 6. In addition, the experiment without PCCI combustion was conducted as reference. Two-stage pilot injection and main injection was adopted. The injection timing for pilot injections were -20 and $-9^{\circ}$ ATDC and the main injection timing was $-2^{\circ}$ ATDC which was the same with previous experiments. The heat input of pilot injection were 61.5 and $65 \mathrm{~J} /$ cycle, respectively, and the that of main injection was also $1283.5 \mathrm{~J} /$ cycle.

Table 6. The injection parameters of the experiments with various main injection timing.

\begin{tabular}{c|c|c} 
& $\begin{array}{c}\text { Sub- } \\
\text { injection }\end{array}$ & Main injection \\
\hline Heat input [J/cycle] & 360 & 1050 \\
\hline Injection timing [ $\left.{ }^{\circ} \mathrm{ATDC}\right]$ & -60 & $-2,0,2,4,6$ \\
\hline Fuel & $\begin{array}{c}r_{i-\mathrm{C} 8 \mathrm{H} 18} \\
=83 \%\end{array}$ & Diesel \\
\hline
\end{tabular}

The results of in-cylinder pressure and heat release rate as the function of crank angle are shown in Figure 7. The experiment result without PCCI combustion is shown in broken lines. With the retard of the main injection timing, the heat release of main injection retarded. The heat release peak of the sub injection could be recognized near $3^{\circ}$ ATDC when the main injection timing was later than $2^{\circ} \mathrm{ATDC}$. When the heat release peak of sub and main injection was separated $\left(\theta_{\text {main }}=2,4,6^{\circ}\right.$ ATDC), the heat release shape of the main injection showed little changes. Therefore, the overlapped heat release rate could be considered as the simple integrate of the heat release rate of sub and main combustion.

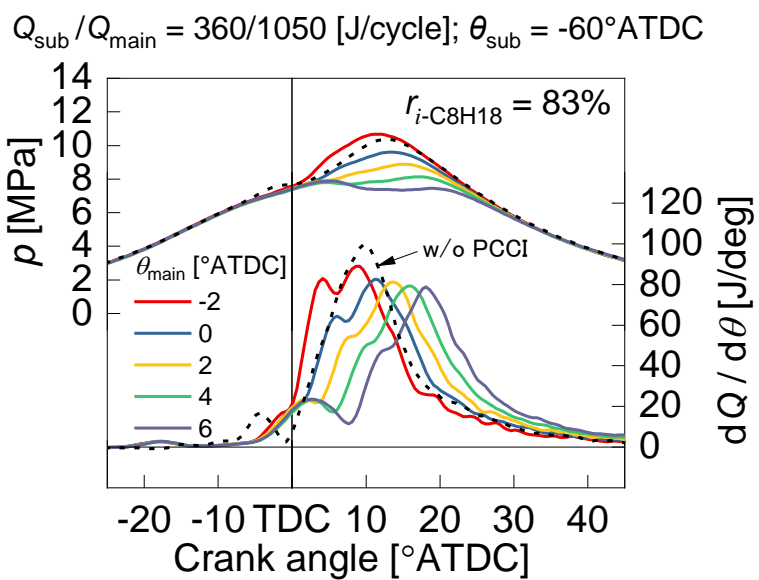

Fig. 7 The in-cylinder pressure and heat release rate shape with various main injection timing.

The results of engine performances are shown on Figure 8 . With the retard of $\theta_{\text {main }}$, the DCV decreased but the $X_{Q_{\mathrm{c}}}$ did not change so much. Therefore, the $\eta_{i-g r o s s}$ decreased when $\theta_{\text {main }}$ was retarded. The emission characteristics are shown on Figure 9. The THC emission did not change with the $\theta_{\text {main }}$. Thus, we could assume that the THC was mainly formed by the over lean of the sub injection fuel. The $\mathrm{CO}$ and smoke emissions showed the same trend with the change of $\theta_{\text {main }}$. This trend is typical for diesel combustion. The fuel rich region of the diesel spray may produce $\mathrm{CO}$ and smoke emissions at the same time. In this case, with the retard of $\theta_{\text {main }}$, the in-cylinder density and temperature will be lower since the main combustion occurs at the expansion stroke. As a result, the oxidization of the $\mathrm{CO}$ and smoke emissions was suppressed due to the low average in-cylinder temperature. In addition, for the same reason, the formation of thermal NOx will be suppressed.

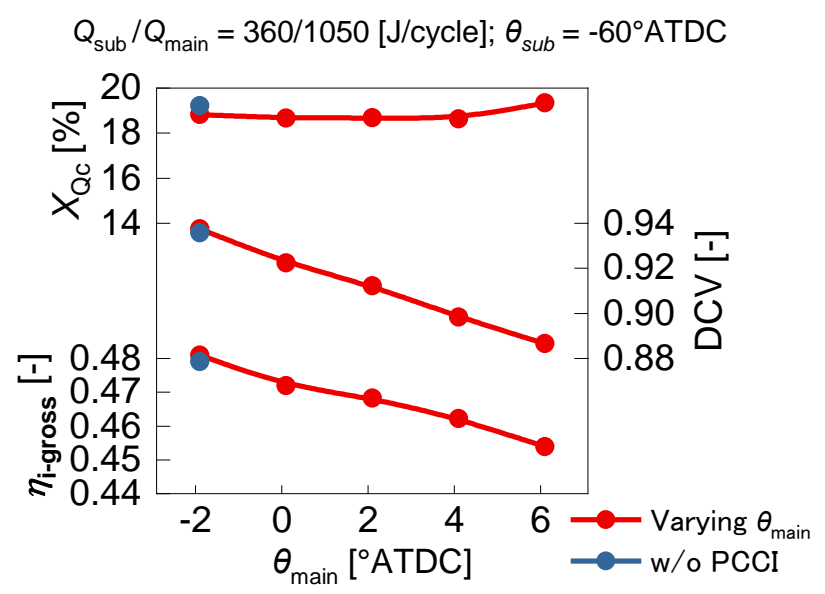

Fig. 8 The engine performance with various main injection timing.

When $\theta_{\text {main }}$ was the same, the smoke emission level was almost the same between the experiment with and without PCCI 
combustion. Therefore, it could be inferred that when PCCI combustion was introduced at the early stage, the air entrainment of the main spray was not disrupted as we expected. However, the THC and CO emission increased due to the PCCI combustion.

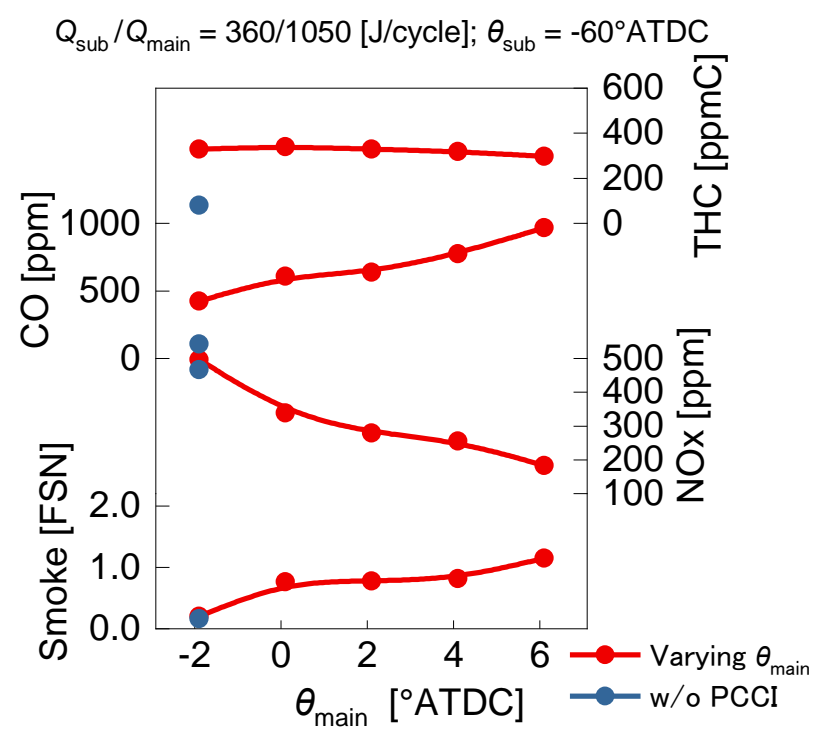

Fig. 9 The emission characteristics with various main injection timing.

\subsection{The experiments with various sub injection quantity}

According to the concept of this combustion strategy, the cooling loss could be reduced by increasing the heat input ratio of sub injection. In order to justify this concept, to which extent the PCCI combustion is beneficial to the cooling loss reduction should be investigated. Therefore, in this section, the sub injection quantity was verified.

While the original heat input for sub injection was fixed to $360 \mathrm{~J} /$ cycle, in this section, the heat input was varied from 288 , 360,432 , to $504 \mathrm{~J} /$ cycle which correspond to $80 \%, 100 \%, 120 \%$ $140 \%$ of $360 \mathrm{~J} /$ cycle. The fuel with $83 \%$ of isooctane was used for sub injection. The total heat input was maintained at $1410 \mathrm{~J} / \mathrm{cycle}$ which was the same with the previous section. The injection parameters can be found on Table 7 .

Table 7. The injection parameters of the experiments with various sub injection quantity and fixed total injection quantity.

\begin{tabular}{c|c|c} 
& Sub-injection & Main injection \\
\hline \hline \multirow{3}{*}{$\begin{array}{c}\text { Heat input } \\
{[\mathrm{J} / \text { cycle }]}\end{array}$} & 288 & 1122 \\
\cline { 2 - 3 } & 360 & 1050 \\
\cline { 2 - 3 } & 432 & 978 \\
\hline $\begin{array}{c}\text { Injection timing } \\
{\left[{ }^{\circ} \text { ATDC }\right]}\end{array}$ & 504 & 906 \\
\hline Fuel & -60 & -2 \\
\hline
\end{tabular}

The results of in-cylinder pressure and heat release rate are shown on Figure 10 and the engine performance results are summarized in Figure 11. The experimental result without PCCI combustion is also listed as reference. In the heat release rate curves, the first small peak around $-18^{\circ}$ ATDC is due to the heat release by low-temperature oxidation from PCCI combustion. The second peak is caused by the heat release of the main injection in the premixed combustion phase. The third peak is due to the heat release of diesel combustion in the mixing-controlled combustion phase. The heat released by PCCI combustion can be observed between the first and the second peak, especially when $Q_{\text {sub }}$ was small.

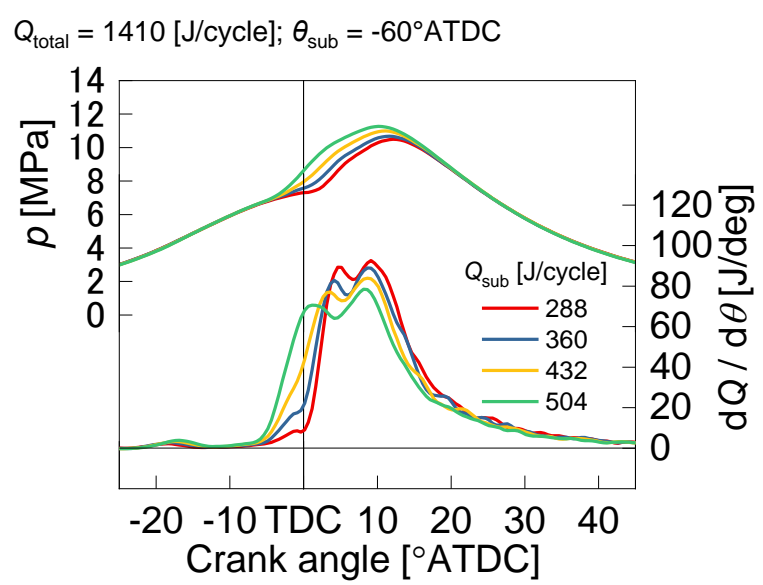

Fig. 10. The in-cylinder pressure and heat release rate shape with various sub injection quantity and fixed total injection quantity.

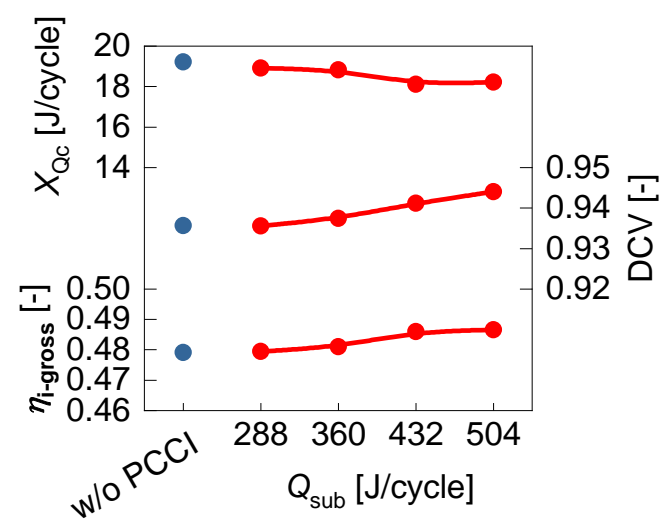

Fig. 11 The engine performance with various sub injection quantities.

When the ratio of $Q_{\text {sub }}$ is increases, the temperature of the burned gas and burning gas produced by PCCI combustion will also increase. The spray tip of main injection was heated by those gases at a higher temperature leading to shorter ignition delay. Based on this assumption, the premixed combustion phase of the main combustion should advance with the increase of the ratio of $Q_{\text {sub }}$. This is in agreement with the result shown in Figure 11. The cooling loss decreased slightly by applying PCCI combustion and it was further reduced by increasing the ratio of $Q_{\text {sub }}$. Commonly, the DCV may show the same trend with cooling loss. However, in this series of experiments, the DCV increased with the reduction of cooling loss. Therefore, although the cooling reduction was not significant, the expected target of improving DCV and depressing cooling loss at the same time were achieved by combining PCCI combustion with conventional diesel combustion. As a result, the $\eta_{i-\text { gross }}$ increased slightly (about $1 \%$ ). 


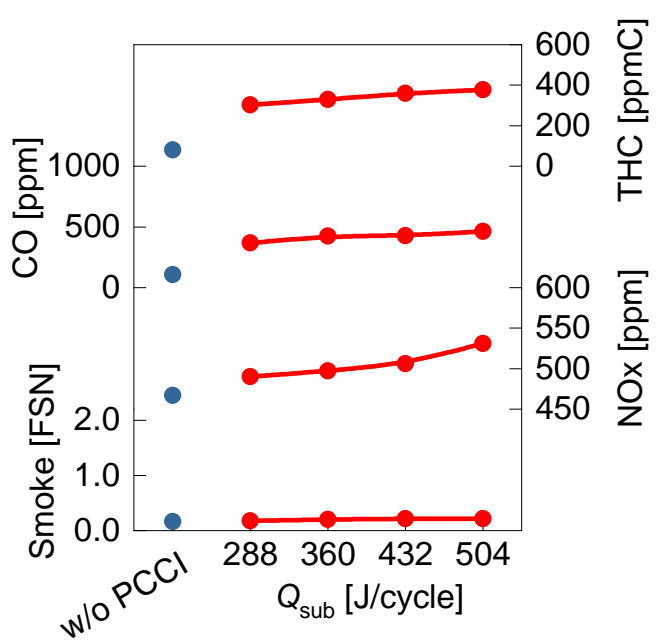

Fig. 12 The emission characteristics with various sub injection quantities.

The emission results are shown on Figure 12. THC and CO emissions did not show obvious change with the increase of $Q_{\text {sub }}$. For PCCI combustion, the over-lean mixture formed by subinjection could be avoided with larger $Q_{\text {sub }}$. Thus the CO and THC emissions may decrease. On the other hand, when $Q_{\text {main }}$ is decreased to maintain the same total heat input, the in-cylinder temperature after diesel combustion should decrease. Which results in the deceleration of THC oxidation. Therefore, the overall THC emission level was almost the same when $Q_{\text {sub }}$ was modified. However, compared with the case without PCCI combustion, THC emission was higher, which was the same as the previous section.

The NOx emission was higher when PCCI combustion was applied even the $Q_{\text {main }}$ was reduced compared with the condition without PCCI combustion. When $Q_{\text {sub }}$ is increased, sub mixture uniformity is deteriorated. Fuel rich regions may still exist when ignition starts, thus, the PCCI combustion temperature will be higher. When main mixture interacts with the sub mixture with higher temperature, larger amount of NOx will be formed. Even if the $Q_{\text {main }}$ is decreased with the increase of $Q_{\text {sub }}$, if this NOx formation mechanism plays the main role, NOx may tend to increase. As a result, the NOx emission increased with the increase of $Q_{\text {sub }}$. In addition, the increase of PCCI combustion temperature could enhance the heat exchange with piston bowl surface. This could be considered as one reason of why further cooling loss reduction was failed by increasing sub injection ratio.

The amount of smoke emission was almost unchanged, too. The smoke emission was supposed to be lower since the main spray impingement on chamber wall will be suppressed when $Q_{\text {sub }}$ is increased. However, since the original smoke emission level without PCCI combustion was already low enough, the smoke reduction effect of higher ratio of PCCI combustion was not demonstrated.

In summary, a slight cooling reduction and improvement of DCV were achieved by increasing sub injection quantity ratio. Since some fuel rich region may still exist in sub mixture, the combustion of these regions produce high temperature flame. Therefore, in order to acquire larger cooling loss reduction effect, more homogeneous sub mixture should be formed before ignition.

\section{Conclusions}

In this experiment, a single cylinder diesel engine was used to further investigate the possibility of DCV increase and cooling loss reduction by combining (premixed charge compression ignition) PCCI and conventional diesel combustion. Isooctane was blended with n-heptane to change the auto-ignition quality of the sub injection fuel. The overlap of PCCI combustion and conventional diesel combustion was achieved. The combustion and emission characteristics of this combined combustion strategy were investigated and the following conclusions were acquired.

- The ignition delay of PCCI combustion could be extended by using high octane number fuel. The cooling loss could be reduced by overlapping the combustion phase of PCCI and conventional diesel combustion.

- When the sub fuel with isooctane volume percentage $\left(r_{i-\mathrm{C} 8 \mathrm{H} 18}\right)$ was $100 \%$, the high temperature heat release of was later than the start of main injection. However, when $r_{i-\mathrm{C} 8 \mathrm{H} 18}$ was lower than $83 \%$, the high temperature heat release of sub injection occurred before the main injection. Main spray may interact with the high temperature gas produced by the sub combustion, hence, its ignition delay was shorter compared with the experiment with $r_{i-\mathrm{C} 8 \mathrm{H} 18}=$ $100 \%$.

- Once the fuel property and injection timing of sub and main injection are fixed, the DCV could be increased by increasing the injection quantity ratio of sub injection. The cooling loss could be reduced slightly with the increase of DCV.

- When sub heat input ration is increased, fuel rich regions may still exist when ignition starts. Thus, the PCCI combustion temperature will be higher. When main mixture interacts with the sub mixture with higher temperature, larger amount of NOx will be formed.

\section{Acknowledgements}

The authors would like to thank Masayoshi Furukawa and Takuji Yokoyama for their valuable assistance with the experiments. This work was supported by the Council for Science, Technology and Innovation Promotion Program (SIP), "Innovative combustion technology" (funding agency: JST).

This paper is written based on a proceeding presented at JSAE 2019 Annual Congress (Spring) .

\section{References}

(1) Onishi, Shigeru, et al. "Active thermo-atmosphere combustion (ATAC) - a new combustion process for internal combustion engines." SAE Transactions (1979): 1851-1860, doi:10.4271/790501.

(2) Noguchi, Masaaki, et al. A study on gasoline engine combustion by observation of intermediate reactive products during combustion. No. 790840. SAE Technical Paper, 1979, doi:10.4271/790840.

(3) Najt, Paul M., and David E. Foster. "Compression-ignited homogeneous charge combustion." SAE Transactions (1983): 964-979, doi:10.4271/830264.

(4) Yanagihara H, Sato Y, Mizuta J. A simultaneous reduction of NOx and soot in diesel engines under a new combustion system (uniform bulky combustion system-UNIBUS). 17th 


\section{Zhichao Bao et al / International Journal of Automotive Engineering}

Vol.10, No.4(2019)

International vienna motor symposium, Vienna; 1996. p. 30314.

(5) Kimura, Shuji, et al. New combustion concept for ultra-clean and high-efficiency small DI diesel engines. No. 1999-013681. SAE Technical Paper, 1999, doi:10.4271/1999-01-3681.

(6) Dec, J., "A Computational Study of the Effects of Low Fuel Loading and EGR on Heat Release Rates and Combustion Limits in HCCI Engines," SAE Technical Paper 2002-011309, 2002, doi:10.4271/2002-01-1309.

(7) Eng, J., "Characterization of Pressure Waves in HCCI Combustion," SAE Technical Paper 2002-01-2859, 2002, doi:10.4271/2002-01-2859.

(8) André, M., Walter, B., Bruneaux, G., Foucher, F., MounaimRousselle, C. : Optimizing early injection strategy for diesel PCCI combustion (No. 2009-01-2731), SAE Technical Paper (2009), doi:10.4271/2009-01-2731.

(9) Kiplimo, R., Tomita, E., Kawahara, N., Zhou, S., \& Yokobe, S. : Effects of injection pressure, timing and EGR on combustion and emissions characteristics of diesel PCCI engine (No. 2011-01-1769), SAE Technical Paper (2011), doi:10.4271/2011-01-1769.

(10) Walter, B. and Gatellier, B., "Development of the High Power NADI ${ }^{\mathrm{TM}}$ Concept Using Dual Mode Diesel Combustion to Achieve Zero NOx and Particulate Emissions," SAE Technical Paper 2002-01-1744, 2002, doi: 10.4271/2002-01-1744

(11) Takeda, Y., Keiichi, N., and Keiichi, N., "Emission Characteristics of Premixed Lean Diesel Combustion with Extremely Early Staged Fuel Injection," SAE Technical Paper 961163, 1996, doi:10.4271/961163.

(12) Nakagome, K., Shimazaki, N., Niimura, K., and Kobayashi, S., "Combustion and Emission Characteristics of Premixed Lean Diesel Combustion Engine," SAE Technical Paper 970898, 1997, doi:10.4271/970898.

(13) Akagawa, H., Miyamoto, T., Harada, A., Sasaki, S. et al., "Approaches to Solve Problems of the Premixed Lean Diesel Combustion," SAE Technical Paper 1999-01-0183, 1999, doi:10.4271/1999-01-0183.

(14) Hashizume, T., Miyamoto, T., Hisashi, A., and Tsujimura, K., "Combustion and Emission Characteristics of Multiple Stage Diesel Combustion," SAE Technical Paper 980505, 1998, doi:10.4271/980505.

(15) Z. Bao., W.K. Pan., T. Yokoyama., K. Hirayama., N. Horibe., H. Kawanabe., T. Ishiyama., "Study on Characteristics of Combined PCCI and Conventional Diesel Combustion," SAE Technical Paper 2019-01-2170,

(16) Kitano, K., Nishiumi, R., Tsukasaki, Y., Tanaka, T. et al., "Effects of Fuel Properties on Premixed Charge Compression Ignition Combustion in a Direct Injection Diesel Engine," SAE Technical Paper 2003-01-1815, 2003, doi:10.4271/200301-1815.

(17) Yao, M., Zheng, Z., Zhang, B., and Chen, Z., "The Effect of PRF Fuel Octane Number on HCCI Operation," SAE Technical Paper 2004-01-2992, 2004, doi:10.4271/2004-012992.

(18) Bunting, B. G., Wildman, C. B., Szybist, J. P., Lewis, S., \& Storey, J. (2007). Fuel chemistry and cetane effects on diesel homogeneous charge compression ignition performance, combustion, and emissions. International Journal of Engine Research, 8(1), 15-27. doi:10.1243/14680874JER01306.

(19) Murphy, M.J., Taylor, J.D., McCormick, R.L. : Compendium of Experimental Cetane Number Data, NREL/SR-540-36805 (2004)

(20) Kalghatgi, G. T., et al. "Low-NOx, Low-Smoke Operation of a Diesel Engine Using 'Premixed Enough'Compression Ignition-Effects of Fuel Autoignition Quality, Volatility and Aromatic Content." THIESEL 2010 Conference on Thermo- and Fluid Dynamic Processes in Diesel Engines, Valencia, Spain, September. 2010. 